\title{
Anion Effect on the Electropolymerization Reaction of Metanil Yellow in Aqueous Media and Characterization of Polymer Films
}

\author{
László Kiss ${ }^{1,2 *}$, András Kiss¹, Sándor Kunsági-Máté2,3 \\ 1 Department of General and Physical Chemistry, Faculty of Sciences, University of Pécs, Ifjúság street 6, H-7624 Pécs, Hungary \\ 2 Szentágothai Research Centre, University of Pécs, Ifjúság útja 20, H-7624 Pécs, Hungary \\ ${ }^{3}$ Department of Organic and Pharmacological Chemistry, Medical School, University of Pécs, Honvéd street 1, H-7624 Pécs, \\ Hungary \\ * Corresponding author, e-mail: kissl@gamma.ttk.pte.hu
}

Received: 15 April 2020, Accepted: 17 July 2020, Published online: 24 November 2020

\begin{abstract}
The electropolymerization of Metanil Yellow was investigated in aqueous solutions containing inorganic acids (sulphuric, hydrochloric, nitric, phosphoric and perchloric acid) as well as sulphonic acids (5-sulpho salicylic acid, sulphanilic acid, dodecylbenzene sulphonic acid, 4-(2-hydroxyethyl)-1-piperazineethanesulfonic acid) and lauryl sulphate in its acidic solution. By the inorganic ions the conductivity increased in the sulphate, chloride, nitrate, perchlorate serie. Of the organic sulphonic compounds 5-sulpho-salicylic acid was found to be a very efficient dopant in increasing polymer conductivity being obviously better than the other sulphonate anions. The formed conducting polymer was not suitable for detection of the corresponding anion. Nitrite ions completely diminished the electric properties of the polymer due to the reaction resulting nitrosamine.
\end{abstract}

Keywords

Metanil Yellow, conducting polymer, sulphonate ion, anion effect

\section{Introduction}

Metanil Yellow (or Yellow 36) is an azo dye used mainly in textile industry owing to its intense color in solutions depending on the $\mathrm{pH}$, and some analytical methods are based on its favorable spectral properties [1-5]. Especially spectrophotometric procedures provide useful alternatives for sensitive detection of different species. These advantageous properties are due to the nitrogen-nitrogen double bond found in it inserted between two phenyl groups (Fig. 1).

Electrochemistry of Metanil Yellow has been also investigated as the azo group can be easily reduced and the diphenylamine moiety can be oxidized. Electrochemical applications utilize also its favorable spectral properties namely<smiles>O=S(=O)([O-])c1ccc(/N=N/c2cccc(Nc3ccccc3)c2)cc1</smiles>

Fig. 1 Structural formula of Metanil Yellow high absorbance in the visible wavelength range like in solar power generation playing the role of sensitizer on $\mathrm{TiO}_{2} / \mathrm{Ti}$ electrode in a photoelectrochemical cell $[6,7]$. The use of carbon quantum dot modified glassy carbon electrode proved its usefulness in detection of Metanil Yellow [8].

Metanil Yellow is a toxic material for animals and human beings having mutagenic properties therefore its degradation is also a significant research interest. Many publications are found concerning the chemical and electrochemical destruction of azo dyes especially Metanil Yellow [9-24].

There is a high interest in the electropolymerization reactions of many organic materials. According to our knowledges electropolymerization of Metanil Yellow has not been studied therefore it is the topic of this work.

\section{Experimental}

The chemicals used in the experiments were of analytical grade (Metanil Yellow was the product of Alfa Aesar) and solutions were prepared with twice deionized water. A disc shaped platinum electrode was the working electrode $(1 \mathrm{~mm}$ in diameter, sealed in polyetheretherketone, product 
of eDAQ), a platinum wire served as counter and a standard calomel as reference electrode filled with $1 \mathrm{M} \mathrm{KCl}$. Before each experiment its surface was cleaned by polishing with $0.05 \mathrm{~mm}$ alumina slurry followed by thorough washing with twice deionized water. A potentiostat (Dropsens, Spain) was used for accomplishing the electrochemical experiments which were carried out at room temperature.

\section{Results and discussion}

\subsection{Cyclic voltammetric studies in the presence of different anions}

In the first part of investigations Metanil Yellow was studied in $10 \mathrm{mmol} / \mathrm{L}$ sulfuric acid with cyclic voltammetry between 0 and $1 \mathrm{~V}$ by setting $0.1 \mathrm{~V} / \mathrm{s}$ scan rate. These parameters were applied in all further voltammetric experiments. Ten consecutive voltammograms are displayed in Fig. 2 (a) taken in this solution containing the substrate in $3 \mathrm{mmol} / \mathrm{L}$ concentration. The first curve shows the oxidation of monomer occurring at around $0.8 \mathrm{~V}$ where its peak appears. The $-\mathrm{NH}-$ group between the two benzene moieties oxidizes and the formed cation radical initiates the polymerization attacking the phenyl group of another monomer similarly to electropolymerization of diphenylamine and its derivatives [25-28]. The morphology studies of deposits carried out in these works highlighted their porous structure. On the other hand, spectroelectrochemical studies supported the conducting nature of polymers prepared from diphenylamine and from its derivatives, copolymers. From the second scan an additional oxidation peak showed up at lower potentials $(\sim 0.62 \mathrm{~V})$ and its intensity increased continuously in the further scans indicating the formation of a conducting polymer scarcely soluble in water. The reduction peaks grew in parallel to increase of anodic ones by repeating the scans due to the reduction of the oxidized film at around $0.5 \mathrm{~V}$ serving as a further evidence for the building up of film with low electric resistance. The electropolymerization was repeated in $\mathrm{pH}=12$ basic solution (Fig. 2 (b)) and formation of a thin insulating polymer resulted. According to these findings acidic media provide the possibility of creating a polymer layer with conducting properties similarly to the usual observations in case of diphenylamine derivatives. The substrate becomes protonated on its - $\mathrm{NH}$ - group indicated also by the color change of solution and this form facilitates the formation of polymer. The rate determining step is the migration of anions into the growing polymer layer accompanying the electrooxidation of the film as the mobility of protons is extraordinarily high compared with any anion.
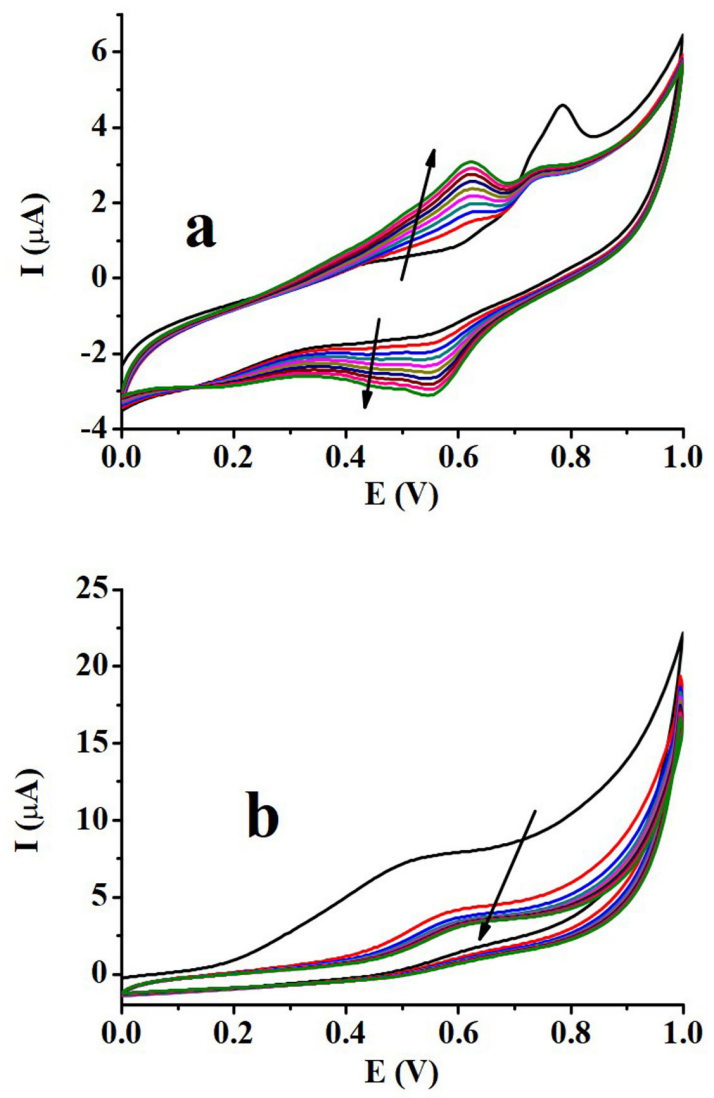

Fig. 2 Subsequent voltammograms of $3 \mathrm{mmol} / \mathrm{L}$ Metanil Yellow in $10 \mathrm{mmol} / \mathrm{L}$ sulphuric acid (a) and in $10 \mathrm{mmol} / \mathrm{L} \mathrm{NaOH}$ solution (b)

The experiments were repeated with other acids in $10 \mathrm{mmol} / \mathrm{L}$ concentration. Fig. 3 contains the peak current values measured in solution of $3 \mathrm{mmol} / \mathrm{L}$ Metanil Yellow electrooxidation for each inorganic ion (introduced by addition of the corresponding acid). Chloride ions resulted in a more conducting polymer than in case of sulphate. The $\mathrm{H}_{2} \mathrm{PO}_{4}^{-}$ions were introduced into the solution by dissolving $\mathrm{H}_{3} \mathrm{PO}_{4}$. Interestingly, highly conducting deposit

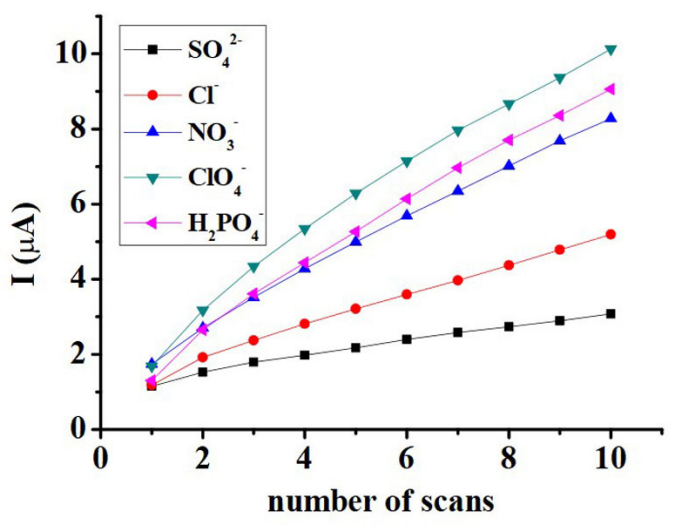

Fig. 3 The peak current values of the subsequent voltammograms for the different inorganic anions $(c=10 \mathrm{mmol} / \mathrm{L})$ 
formed in the presence of perchlorate ions. The observed trend in increment of peak current increase is in accordance with the chaotropic nature of ions. The relatively small and doubly charged sulphate ions have an organized hydrate shell and losing water molecules needs higher activation energy preventing their insertion into the growing polymer to compensate the forming positive charges during its electrooxidation. Therefore, the singly charged and larger perchlorate ions contribute to the enhanced growth of highly conducting polymer.

It is known that sulphonate ions are suitable dopants for increasing the conductivity of the polymer film [29], therefore experiments were carried out also with them. It is mainly true for polyaniline which has diverse applications [30]. On the other hand, in our earlier works [31, 32] we demonstrated that organic compounds bearing amino groups can be easily oxidized electrochemically. Preliminary voltammetric studies of the sulphonate ions show that none of them has redox activity between 0 and $1 \mathrm{~V}$ except for sulphanilic acid (Fig. 4). The latter compound oxidized close to $1 \mathrm{~V}$ and the products underwent electroreduction at around $0.33 \mathrm{~V}$ where a smaller cathodic peak appeared.

Fig. 5 reveals the recorded voltammograms for Metanil Yellow in presence of 5-sulpho salicylic acid. The very high anodic peaks indicate that this ion acts as an efficient dopant. In the reverse scans the two cathodic peaks also increase similarly by increasing the number of scans at smaller potentials where the electroreduction of the oxidized film takes place. The appearance of a second reduction peak immediately after the first former peak can be observed, where electroreduction of the azo group to hydrazo group occurs according to an earlier work of Shereema et al. [8], which is then oxidized back to azo

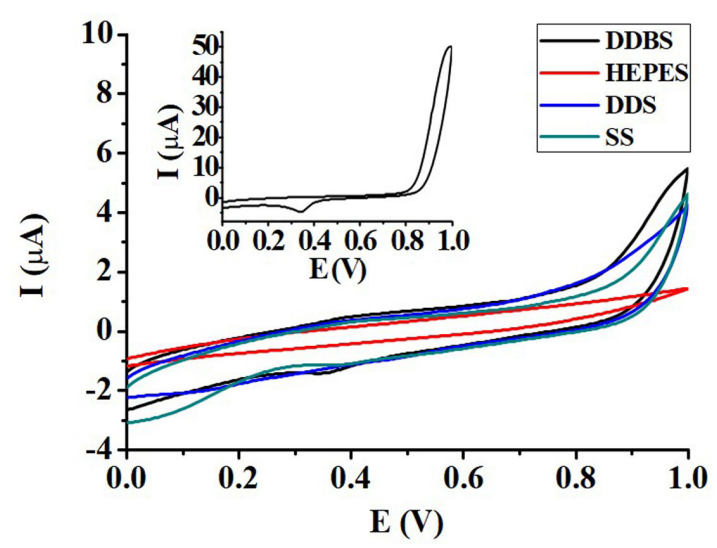

Fig. 4 Cyclic voltammograms of the investigated sulphonate anions (scan rate $0.1 \mathrm{~V} / \mathrm{s}, c=10 \mathrm{mmol} / \mathrm{L}$ ), inset graph is related to sulphanilic acid
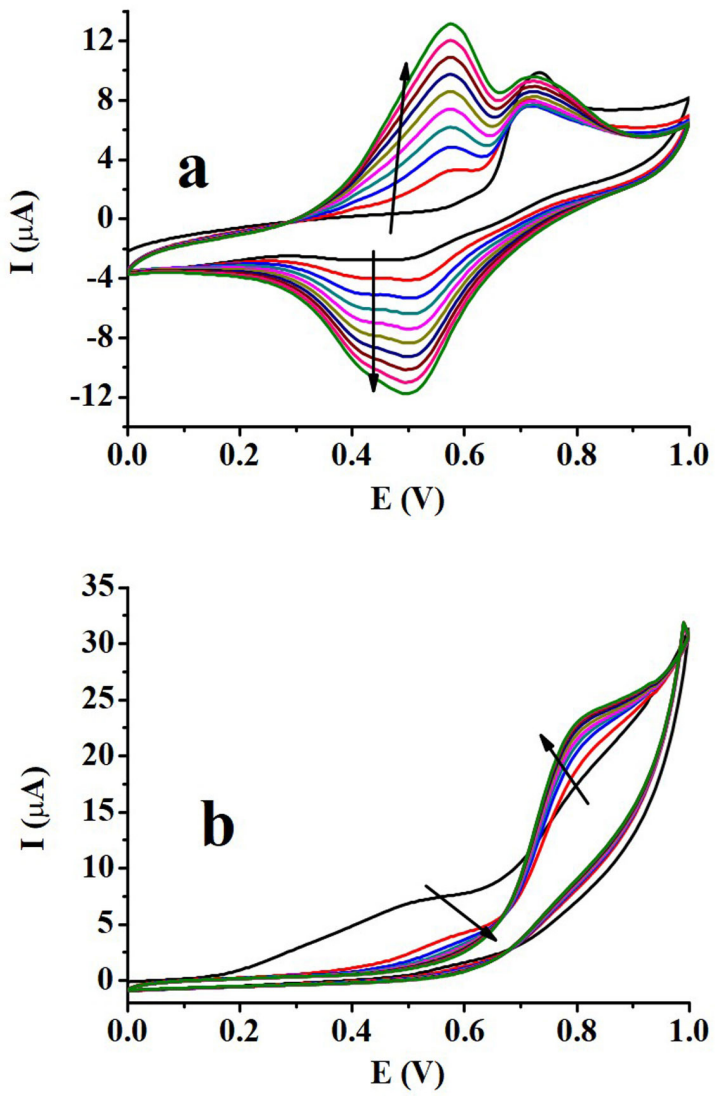

Fig. 5 Consecutive voltammograms of $3 \mathrm{mmol} / \mathrm{L}$ Metanil Yellow in presence of $10 \mathrm{mmol} / \mathrm{L} 5$-sulpho salicylic acid (a) and $10 \mathrm{mmol} / \mathrm{L}$ 5 -sulpho salicylate ions in basic solution (b)

group in the next scan. Similarly to the previous findings in basic solution of 5-sulpho-salicylate ions only insulating film develops (Fig. 5 (b)). It also indicates that only acidic environment provides the appropriate conditions for increasing the electric conductivity of the forming polymer. In the $10 \mathrm{mmol} / \mathrm{L}$ solution of dodecyl sulphate salt containing $3 \mathrm{mmol} / \mathrm{L}$ Metanil Yellow and $10 \mathrm{mmol} / \mathrm{L}$ sulphuric acid was also dissolved to ensure the acidic $\mathrm{pH}$ in the solution. Earlier, sulphate ions did not prove efficient at all in triggering the formation of highly conducting polymer therefore its interference is not significant. The other sulphonate ions also did not facilitate the formation of highly conducting polymer (Fig. 6). However, they are also strong acids with $p K_{a}$ below 1 except for HEPES whose first $p K_{a}$ is 3 . Their size proved to be too large as during their insertion into the depositing organic layer they influence unfavorably its electric properties.

The tendency of the peak currents in case of sulphanilic acid differ remarkably from that of the other sulphonate ions. The peak heights of the first voltammograms are similar to that of 5-sulpho salicylic acid but after the third cycle 


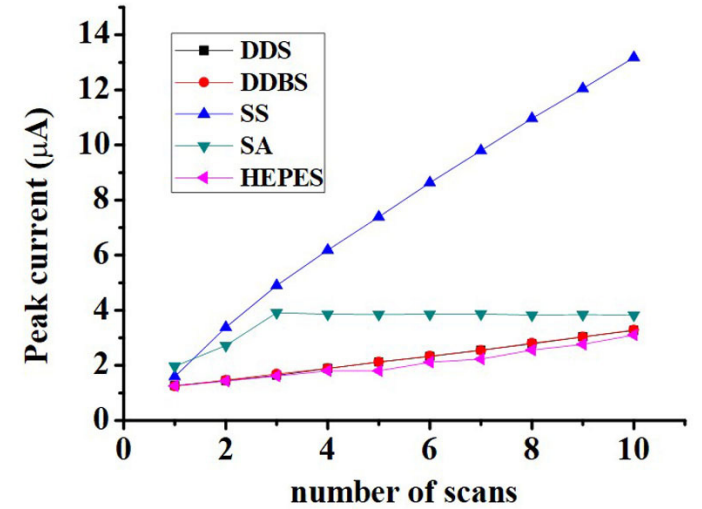

Fig. 6 Peak currents for $3 \mathrm{mmol} / \mathrm{L}$ Metanil Yellow in the presence of the different organic sulphonate ions (DDS: dodecyl sulphate, DDBS: dodecylbenzene sulphonate, SS: 5-sulpho salicylic acid, SA: sulphanilic acid, HEPES: 4-(2-hydroxyethyl)-1-piperazineethanesulfonic acid)

the peak currents reach a steady-state value. As sulphanilic acid is a zwitterion its positive charge repels the forming positive charges of polymer hindering the further building of the layer. The steady value of peak currents from the third scan can be attributed to the reoxidation of the previously deposited thin film. The results obtained with this material and with 5-sulpho salicylic acid show that their size is appropriate for electropolymerization of Metanil Yellow. Its voltammograms contain also the cathodic peak of attributable to sulphanilic acid oxidation products (Fig. 7). Its height increased until a saturation was reached indicating the accumulation of sulphanilic acid in the thin layer oxidized previously in the anodic part.

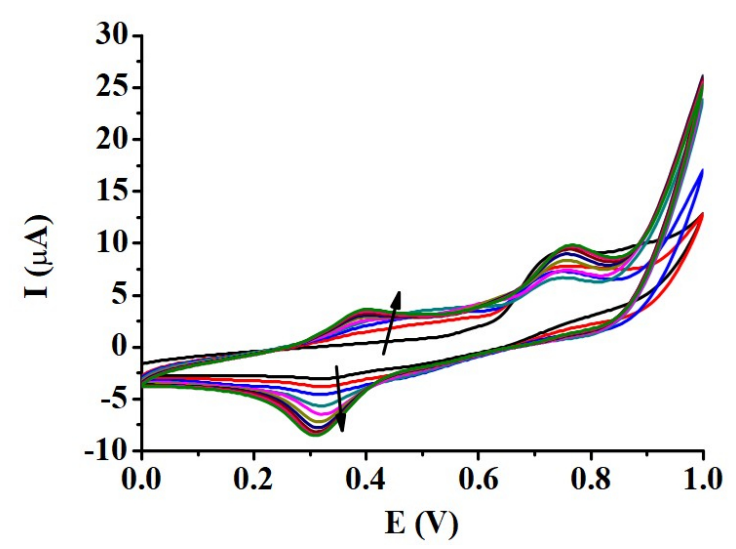

Fig. 7 Subsequent cyclic voltammograms of $3 \mathrm{mmol} / \mathrm{L}$ Metanil Yellow in an aqueous solution containing $10 \mathrm{mmol} / \mathrm{L}$ sulphanilic acid (scan rate $0.1 \mathrm{~V} / \mathrm{s}$ )

\subsection{Dependence of anodic peak currents on the scan rate}

The investigation of the effect of changing the scan rate provides useful information concerning the behavior of the studied process. It was studied by all of ions being efficient in contributing to the higher polymer conductivity. In the previous experiments, the polymer was electrodeposited by repeating the scanning ten times. After this step the platinum electrode covered by the layer was kept in water enhancing the diffusion of unreacted monomers from the films. Then, the electrode was put into the $10 \mathrm{mmol} / \mathrm{L}$ aqueous solution of the corresponding acid and the cyclic voltammograms were repeated until they reached an almost steady value and during this procedure the traces of monomer presenting in the film were oxidized. Before all recordings the potential was kept for $30 \mathrm{~s}$ at $0 \mathrm{~V}$ for the complete reduction of the oxidized film followed by $30 \mathrm{~s}$ equilibration period.

The obtained $I_{p a}$ vs. scan rate plot is displayed in Fig. 8 for Metanil Yellow in presence of 5-sulpho salicylic acid. The figure clearly shows the linear dependence of anodic peak currents on the scan rate indicating that electrooxidation of the polymer is adsorption controlled. It was established also by the other studied ions. As a matter of fact the electroactive polymer is confined to the platinum surface and anions migrate from bulk into the polymer to compensate the forming positive charges.

\subsection{Effect of nitrite ions}

In samples containing nitrate ions nitrite is one of the possible interfering ions which is a product of nitrate reduction.

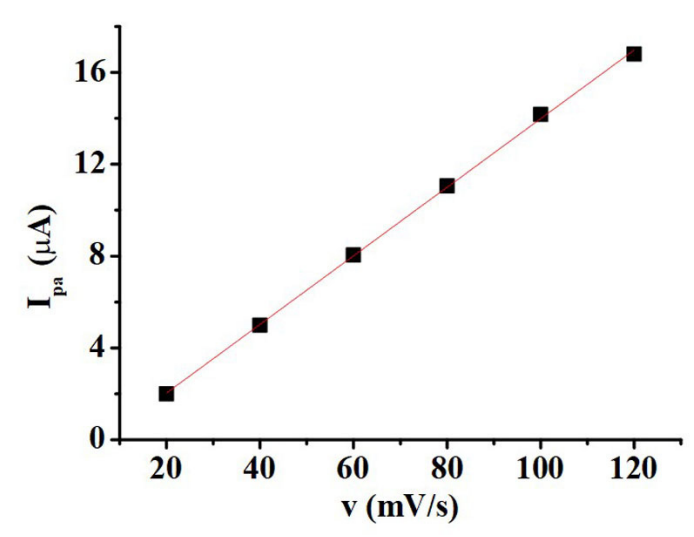

Fig. 8 Dependence of anodic peak currents on the scan rate for the polymer formed from Metanil Yellow in aqueous solution of $10 \mathrm{mmol} / \mathrm{L} 5$-sulpho salicylic acid 
The electrodeposited polymer coated electrode was exposed to nitrite ion in neutral and acidic conditions. First of all the coating was completely reduced at $0 \mathrm{~V}$ according to the procedure described in the previous section to be able to oxidize to get the corresponding oxidation peak. In neutral media where only sodium nitrite was dissolved in 10 and $20 \mathrm{mmol} / \mathrm{L}$ concentration (Fig. 9) and no anodic peak appeared at around the potential where it appeared in solution of Metanil Yellow containing nitric acid. Close to $1 \mathrm{~V}$ steep current increases were observed possibly due to electrooxidation of nitrite ions. The experiments were repeated containing nitric acid in $10 \mathrm{mmol} / \mathrm{L}$ concentration ensuring the acidic environment (inset of Fig. 9). The same results could be obtained as in neutral media which also facilitates that electrooxidation of nitrite ions occur after diffusion through the porous film. No anodic peak showed up also in presence of nitrate ions as observed previously in their absence. These results suggest that determination of nitrate ions encounters difficulties due to nitrite ions and the layer has rather diffusion hindering properties towards electroactive species. The reason is the reaction of nitrite ions with the amine type groups of the polymer which was facilitated particularly in acidic medium producing nitrosoamine usually observed by secondary amines which showed no electroactivity and the coating lost its favorable conductivity. When the polymer is reduced electrochemically in the pretreatment, amine type groups form, eliciting the further reaction with nitrite. Exposition to nitrite ions changed the color of layer from light purple to light yellow characteristic for nitrosamines.

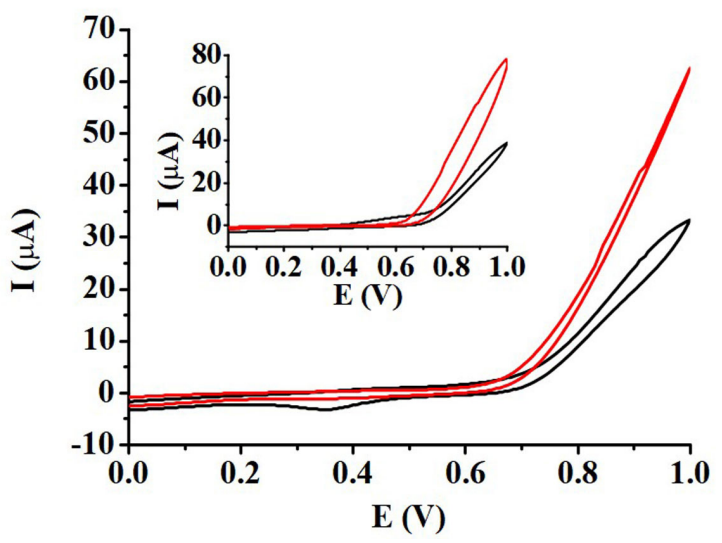

Fig. 9 Effect of $\mathrm{pH}$ on the electrooxidation of nitrite ions on electropolymerized Metanil Yellow coated Pt electrode (inset graph is related to acidic $\mathrm{pH}$ )

\subsection{Effect of acid concentration}

The experimental findings in the previous sections highlighted that electropolymerized Metanil Yellow sustains its highly conducting properties only at low pHs. Influence of acid concentration might provide additional useful information about the electropolymerization process. Recording of ten subsequent voltammograms of $3 \mathrm{mmol} / \mathrm{L}$ Metanil Yellow at different acid concentrations and taking into account the anodic peak currents of the tenth cycles showed that in cases when concentration of substrate and acid was comparable (Fig. 10) the highest peak currents could be obtained. These results suggest that less quantity of acid (approximately 0.2 times that of substrate) seems enough compared with substrate to obtain electropolymerized Metanil Yellow. As Metanil Yellow itself is also a strong electrolyte the substrate is in aqueous system in an anionic form so in presence of another added electrolyte in less quantity leads to the predominant role of migration effects on the electrooxidation of substrate.

\subsection{Estimation of the electropolymerized Metanil Yellow in determination of anion concentration}

In the previous paragraphs it was shown that electropolymerization of Metanil Yellow reflects the presence of different anions with different sensitivity. According to the previous sections the polymer layer was conditioned before each measurement setting $30 \mathrm{~s}$ conditioning time at $0 \mathrm{~V}$ and then $30 \mathrm{~s}$ equilibration time. Calibration solutions were prepared which contained sulphuric acid in $5 \mathrm{mmol} / \mathrm{L}$ concentration and the concentration of salt

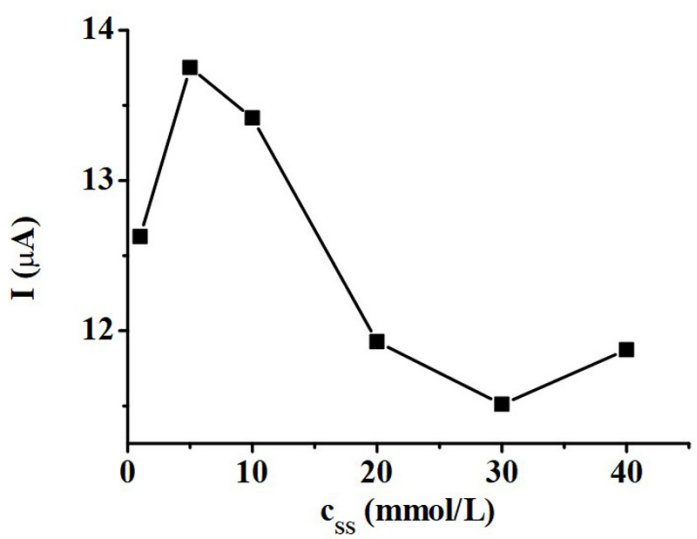

Fig. 10 The peak currents of tenth scans of Metanil Yellow electrooxidation by different 5 -sulpho salicylic acid concentrations (scan rate $0.1 \mathrm{~V} / \mathrm{s}$ ) 
containing the corresponding anion. The presence of sulphuric acid ensured the acidic $\mathrm{pH}$ to contribute to formation of the highly conducting polymer. The responses of the polymer modified electrode towards $\mathrm{ClO}_{4}^{-}$and $\mathrm{NO}_{3}^{-}$ ions are plotted in Fig. 11. Concentrations of these ions were set by adding $\mathrm{NaClO}_{4}$ and $\mathrm{NaNO}_{3}$ in the necessary quantity. The measured peak currents show that they are practically independent on the anion concentration. The observations are in good agreement with the previous findings as the electroactive polymer is in the very close vicinity of the platinum surface and its electrochemical reaction needs only the presence of anions in the electrolyte solution capable of entrapment into the growing film.

The reproducibility of the electrodeposition was also studied in case of different anions and Table 1 summarizes the results. The data for the tenth cycle were taken into consideration for three measurement $(N=3)$ by the statistical evaluation. As seen earlier from the figures and these data show that anodic and cathodic peak heights are comparable in magnitude and reproducibility of deposition is around $5 \%$.

\section{Conclusion}

The electrochemical investigations of Metanil Yellow showed that conducting polymer might be electrodeposited which is strongly dependent on the type of anion presenting in the acidic electrolyte solution. During electrooxidation of polymer it takes off the anions and strip into the solution during the electroreduction so its future application might be in the field of anion removal from aqueous solutions or utilization in processes where transfer of ions is the key process. The deposited film itself and its nitrosamine derivative have potential applications where optical and sorption capability is important.

\section{References}

[1] Jang, M., Cao, G., Paul, J. "Colorimetric Particle Acidity Analysis of Secondary Organic Aerosol Coating on Submicron Acidic Aerosols", Aerosol Science and Technology, 42(6), pp. 409-420, 2008. https://doi.org/10.1080/02786820802154861

[2] Srivastava, L. P., Khanna, S. K., Singh, G. B. "Spectrophotometric Estimation of Metanil Yellow in Foodstuffs", International Journal of Environmental Analytical Chemistry, 5(2), pp. 119-124, 1978. https://doi.org/10.1080/03067317808071137

[3] Ali, E. A., Adawy, A. M., El-Shahat, M. F., Amin, A. S. "Simple spectrophotometric methods for determination of fluoxetine and clomipramine hydrochlorides in dosage forms and in some post-mortem biological fluids samples", Egyptian Journal of Forensic Science, 6(4), pp. 370-380, 2016. https://doi.org/10.1016/j.ejfs.2016.05.007

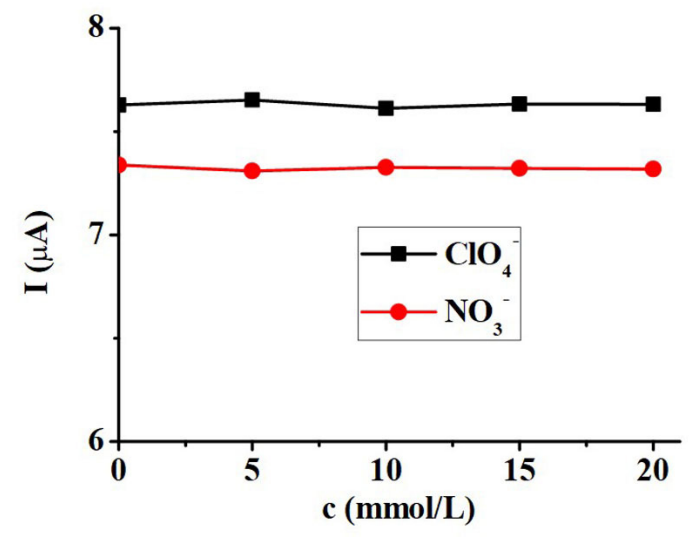

Fig. 11 Dependence of anodic peak currents of electropolymerized Metanil Yellow on the anion concentration

Table 1 Statistical data for the tenth cycles of electrodeposition process in presence of the anions (relative standard deviations in parenthesis)

\begin{tabular}{lcc}
\hline Anion & $\begin{array}{c}\text { Anodic peak current } \\
(\mathrm{mA})\end{array}$ & $\begin{array}{c}\text { Cathodic peak current } \\
(\mathrm{mA})\end{array}$ \\
\hline $\mathrm{SO}_{4}^{2-}$ & $3.094(4.334 \%)$ & $-3.093(3.998 \%)$ \\
$\mathrm{Cl}^{-}$ & $5.299(4.546 \%)$ & $-4.646(4.011 \%)$ \\
$\mathrm{NO}_{3}{ }^{-}$ & $8.09(3.718 \%)$ & $-7.514(3.122 \%)$ \\
$\mathrm{ClO}_{4}^{-}$ & $10.072(3.112 \%)$ & $-9.477(2.776 \%)$ \\
$\mathrm{H}_{2} \mathrm{PO}_{4}{ }^{2-}$ & $9.201(5.201 \%)$ & $-9.231(5.033 \%)$ \\
5 -sulpho salicylate & $12.998(4.888 \%)$ & $-11.685(5.101 \%)$ \\
Sulphanilic acid & $3.724(2.885 \%)$ & No relevant peak \\
\hline
\end{tabular}

\section{Acknowledgement}

Financial support of the GINOP 2.3.2-15-2016-00022 grants is highly appreciated. Special thanks to Szilárd Szili for providing the chemical Metanil Yellow.

[4] Wang, S., Du, L., Zhang, A., Ma, C., Liu, D. "Catalytic spectrophotometric determination of molybdenum (VI) with the hydrazine-metanil yellow system", Microchimica Acta, 124, pp. 49-54, 1996. https://doi.org/10.1007/BF01244956

[5] Kumar, Y. K., Prakash, K. V., Lavanya, G., Pulla, R. P. "A New Extractive Spectrophotometric Method for the Estimation of Alosetron", Journal of Applied Pharmaceutical Science, 4(1), pp. 091-093, 2014. https://doi.org/10.7324/JAPS.2014.40115

[6] Koli, P., Dayma, Y., Pareek, R. K. "Simultaneous electrochemical solar power generation and storage using metanil yellow-formic acid as a new sensitizer-reductant couple in photogalvanic cells", RSC Advances 9(13), pp. 7560-7574, 2019. https://doi.org/10.1039/C8RA10014D 
[7] Nurdin, M., Azis, T., Maulidiyah, M., Aladin, A., Hafid, N. A., Salim, L. O. A., Wibowo, D. "Photocurrent Responses of Metanil Yellow and Remazol Red B Organic Dyes by Using $\mathrm{TiO}_{2} /$ Ti Electrode", IOP Conference Series: Materials Science and Engineering, 367, Article number: 012048, 2018. https://doi.org/10.1088/1757-899X/367/1/012048

[8] Shereema, R. M., Rao, T. P., Sameer Kumar, V. B., Sruthi, T. V., Vishnu, R., Prabhu, G. R. D., Sharath Shankar, S. "Individual and simultaneous electrochemical determination of metanil yellow and curcumin on carbon quantum dots based glassy carbon electrode", Materials Science \& Engineering: C Materials for Biological Applications, 93, pp. 21-27, 2018. https://doi.org/10.1016/j.msec.2018.07.055

[9] Goel, A., Chaudhary, M. "A novel method for oxidative degradation of metanil yellow azo dye by hexacyanoferrate(III) ions", Water Environment Research, 91(1), pp. 69-74, 2019. https://doi.org/10.2175/106143017X15131012188277

[10] Villanueva-Rodríguez, M., Hernández-Ramírez, A., PeraltaHernández, J. M., Bandala, E. R., Quiroz-Alfaro, M. A. "Enhancing the electrochemical oxidation of acid-yellow 36 azo dye using boron-doped diamond electrodes by addition of ferrous ion", Journal of Hazardous Materials, 167, pp. 1226-1230, 2009. https://doi.org/10.1016/j.jhazmat.2008.12.137

[11] Cruz-González, K., Torres-López, O., García-León, A., Guzmán-Mar, J. L., Reyes, L. H., Hernández-Ramírez, A., Peralta-Hernández, J. M. "Determination of optimum operating parameters for Acid Yellow 36 decolorization by electro-Fenton process using BDD cathode", Chemical Engineering Journal, 160(1), pp. 199-206, 2010. https://doi.org/10.1016/j.cej.2010.03.043

[12] Chen, C., Nurhayati, E., Juang, Y., Huang, C. "Electrochemical decolorization of dye wastewater by surface-activated borondoped nanocrystalline diamond electrode", Journal Environmental Sciences-China 45, pp. 100-107, 2016.

https://doi.org/10.1016/j.jes.2016.01.004

[13] Brito, C. N., Ferreira, M. B., de Moura Santos, E. C. M., Línares Léon, J. J., Ganiyu, S. O., Martínez-Huitle, C. A. "Electrochemical degradation of Azo-dye Acid Violet 7 using BDD anode: effect of flow reactor configuration on cell hydrodynamics and dye removal efficiency", Journal of Applied Electrochemistry, 48, pp. 1321-1330, 2018.

https://doi.org/10.1007/s10800-018-1257-4

[14] Kenova, T. A., Kornienko, G. V., Golubtsova, O. A., Kornienko, V. L., Maksimov, N. G. "Electrochemical degradation of Mordant Blue 13 azo dye using boron-doped diamond and dimensionally stable anodes: influence of experimental parameters and water matrix", Environmental Science and Pollution Research, 25, pp. 30425-30440, 2018.

https://doi.org/10.1007/s11356-018-2977-z

[15] Alcocer, S., Picos, A., Uribe, A. R., Pérez, T., PeraltaHernández, J. M. "Comparative study for degradation of industrial dyes by electrochemical advanced oxidation processes with BDD anode in a laboratory stirred tank reactor", Chemosphere, 205, pp. 682-689, 2018.

https://doi.org/10.1016/j.chemosphere.2018.04.155
[16] Saez, C., Panizza, M., Rodrigo, M. A., Cerisola, G. "Electrochemical incineration of dyes using a boron-doped diamond anode", Journal of Chemical Technology and Biotechnology, 82(6), pp. 575-581, 2007. https://doi.org/10.1002/jctb.1703

[17] Juang, Y., Nurhayati, E., Huang, C., Pan, J. R., Huang, S. "A hybrid electrochemical advanced oxidation/microfiltration system using BDD/Ti anode for acid yellow 36 dye wastewater treatment", Separation and Purification Technology, 120, pp. 289-295, 2013. https://doi.org/10.1016/j.seppur.2013.09.042

[18] Ruiz, E. J., Arias, C., Brillas, E., Hernández-Ramírez, A., PeraltaHernández, J. M. "Mineralization of Acid Yellow 36 azo dye by electro-Fenton and solar photoelectro-Fenton processes with a borondoped diamond anode", Chemosphere, 82(4), pp. 495-501, 2011. https://doi.org/10.1016/j.chemosphere.2010.11.013

[19] Xie, Y. B., Li, X. Z. "Interactive oxidation of photoelectrocatalysis and electro-Fenton for azo dye degradation using $\mathrm{TiO}_{2}-\mathrm{Ti}$ mesh and reticulated vitreous carbon electrodes", Materials Chemistry and Physics, 95(1), pp. 39-50, 2006. https://doi.org/10.1016/j.matchemphys.2005.05.048

[20] Zhang, G., Zhao, S., Yang, F., Liu, L. "Electrocatalytic Reduction of Oxygen at Anthraquinonedisulfonate/Polypyrrole Composite Film Modified Electrodes and Its Application to the Electrochemical Oxidation of Azo Dye", Electroanalysis, 21(22), pp. 2420-2426, 2009.

https://doi.org/10.1002/elan.200804664

[21] Wang, A., Qu, J., Liu, H., Ge, J. "Degradation of azo dye Acid Red 14 in aqueous solution by electrokinetic and electrooxidation process", Chemosphere, 55(9), pp. 1189-1196, 2004. https://doi.org/10.1016/j.chemosphere.2004.01.024

[22] Bedolla-Guzman, A., Sirés, I., Thiam, A., Peralta-Hernández, J. M., Gutiérrez-Granados, S., Brillas, E., "Application of anodic oxidation, electro-Fenton and UVA photoelectro-Fenton to decolorize and mineralize acidic solutions of Reactive Yellow 160 azo dye", Electrochimica Acta, 206, pp. 307-316, 2016. https://doi.org/10.1016/j.electacta.2016.04.166

[23] Nie, C., Sun, P., Zhu, L., Gao, S., Wu, H., Wang, B. "Solar-driven advanced oxidation processes for full mineralisation of azo dyes in wastewater", Environmental Chemistry, 14(3), pp. 188-197, 2017. https://doi.org/10.1071/EN16202

[24] Wächter, N., Pereira, G. F., Rocha-Filho, R. C., Bocchi, N., Biaggio, S. R. "Comparative Electrochemical Degradation of the Acid Yellow 49 Dye Using Boron-Doped Diamond, $\beta-\mathrm{PbO}_{2}$, and DSA ${ }^{\circledR}$ Anodes in a Flow Reactor", International Journal of Electrochemical Science, 10, pp. 1361-1371, 2015.

[25] Chang, C., Chen, W., Wen, T., Gopalan, A. "Electrochemical and Spectroelectrochemical Studies on Copolymerization of Diphenylamine with 2,5-Diaminobenzenesulfonic Acid", Journal of The Electrochemical Society, 149(8), pp. E298-E305, 2002. https://doi.org/10.1149/1.1491984

[26] Amouzad, F., Zarei, K. "Layer-by-Layer Electrochemical Assembly of Pt/Phosphomolybdic Acid/Poly(diphenylamine)/PGE for Electrocatalytic Oxidation of Methanol", Journal of Electronic Materials, 49, pp. 3583-3590, 2020. https://doi.org/10.1007/s11664-020-08054-5 
[27] Santhosh, P., Gopalan, A., Vasudevan, T., Lee, K.-P. "Platinum particles dispersed poly(diphenylamine) modified electrode for methanol oxidation", Applied Surface Science, 252(22), pp. 7964-7969, 2006.

https://doi.org/10.1016/j.apsusc.2005.10.002

[28] Wen, T.-C., Sivakumar, C., Gopalan, A. "In-situ spectroelectrochemical evidences for the copolymerization of $o$-toluidine with diphenylamine-4-sulphonic acid by UV-visible spectroscopy", Spectrochimica Acta Part A: Molecular and Biomolecular Spectroscopy, 58(1), pp. 167-177, 2002.

https://doi.org/10.1016/S1386-1425(01)00529-7

[29] Xu, G., Wang, W., Qu, X., Yin, Y., Chu, L., He, B., Wu, H., Fang, J., Bao, Y., Liang, L. "Electrochemical properties of polyaniline in $p$-toluene sulfonic acid solution", European Polymer Journal, 45(9), pp. 2701-2707, 2009.

https://doi.org/10.1016/j.eurpolymj.2009.05.016
[30] Abed, M. Y., Mazrouaa, A. M., Abdeen, Z., Ashery, A. "Synthesis and Characterisation of Some Conducting Polymers and Their Complexed Compounds", Periodica Polytechnica Chemical Engineering, 58(Supplement), pp. 35-41, 2014. https://doi.org/10.3311/PPch.7316

[31] Kiss, L. "Exposure Studies of Different Kinds of Volatile Organic Compounds in Vapour Phase with a Narrow-gap Cell Containing $\mathrm{Cu}_{\mathrm{x}} \mathrm{S}$ Modified Carbon Microdisc Electrode", Periodica Polytechnica Chemical Engineering, 63(1), pp. 170-178, 2019. https://doi.org/10.3311/PPch.11835

[32] Kiss, L., Kovács, F., Kunsági-Máté, S. "Electropolymerization of $N, N^{\prime}$-Diphenylguanidine in Non-Aqueous Aprotic Solvents and Alcohols", Periodica Polytechnica Chemical Engineering, 2020. https://doi.org/10.3311/PPch.14959 